\title{
Produção, caracterização e avaliação biológica de silagens de resíduos de camarão para tilápia-do-nilo
}

\author{
[Production, characterization and biological evaluation of shrimp waste silage for Nile tilapia] \\ L.U. Gonçalves, E.M.M. Viegas* \\ Faculdade de Zootecnia e Engenharia de Alimentos - USP \\ Rua Duque de Caxias Norte, 255 \\ 13635-900 - Pirassununga, SP
}

\begin{abstract}
RESUMO
Elaboraram-se e caracterizaram-se nutricionalmente dois tipos de silagens fermentadas de resíduos de camarão-sete-barbas (Xiphopenaeus kroyeri), alterando-se as fontes de carboidratos. As silagens foram formuladas com resíduo de camarão, $15 \%$ de carboidrato -melaço de cana-de-açúcar (SM) ou varredura da farinha láctea (SF)-, $10 \%$ de iogurte, $0,25 \%$ de ácido sórbico e $1 \%$ de ácido fórmico. Cada silagem foi caracterizada durante a estocagem, por 120 dias, quanto à composição centesimal, nitrogênio não protéico e todas comparadas por meio do teste de digestibilidade in vivo com juvenis de tilápia-do-nilo. Após o $30^{\circ}$ dia de estocagem, observou-se que a SM apresentou maior $(\mathrm{P}<0,05)$ teor de cinzas $(\mathrm{SM}=$ $34,97 \mathrm{~g} \cdot 100 \mathrm{~g}^{-1}$ e $\left.\mathrm{SF}=30,92 \mathrm{~g} \cdot 100 \mathrm{~g}^{-1}\right)$ e menor teor de matéria seca $\left(\mathrm{SM}=20,02 \mathrm{~g} \cdot 100 \mathrm{~g}^{-1}\right.$ e $\mathrm{SF}=21,11 \mathrm{~g} \cdot 100 \mathrm{~g}^{-}$ ${ }^{1}$ ). Os coeficientes de digestibilidade aparente $(\mathrm{CDA})$ e a proteína digestível não diferiram entre os tratamentos $(\mathrm{P}>0,05)$, mas observou-se alta digestibilidade nas dietas $\left(\mathrm{CDA}_{\mathrm{SM}}=78,2 \%\right.$ e $\left.\mathrm{CDA}_{\mathrm{SF}}=73,1 \%\right)$. Independente da fonte de carboidrato, as silagens elaboradas com resíduos de camarão-sete-barbas mantiveram-se estáveis durante 120 dias e podem ser utilizadas como ingrediente de rações para a tilápiado-nilo.
\end{abstract}

Palavras-chave: silagem biológica, resíduos de camarão, Xiphopenaeus kroyeri, Oreochomis niloticus, digestibilidade

\begin{abstract}
Two types of fermented shrimp waste silage (Xiphopenaeus kroyeri) were elaborated and characterized, alternating the sources of carbohydrates. The silages were elaborated with shrimp waste, $15 \%$ of carbohydrate - sugar cane molasses (SM) or "Farine Lactée" (SF) -, 10\% of yogurt, $0.25 \%$ of sorbic acid, and 1\% of formic acid. Each silage was characterized during storage for 120 days on proximate composition and non protein nitrogen, besides nutritionally compared by digestibility trials to Nile tilapia juveniles. After the $30^{\text {th }}$ storage day, it was observed that $S M$ presented higher ashes content (SM= $34.97 \mathrm{~g} .100 \mathrm{~g}^{-1}$ and $S F=30.92 \mathrm{~g} \cdot 100 \mathrm{~g}^{-1}$ ) and lower dry matter content ( $S M=20.02 \mathrm{~g} \cdot 100 \mathrm{~g}^{-1}, \quad S F=$ 21.11 g. $\left.100 \mathrm{~g}^{-1}\right)$. The apparent digestibility $(A D C)$ and digestible protein coefficients did not vary between trials $(P>0.05)$, but higher digestibility in the diets $\left(A D C_{S M}=78.2 \%, A D C_{S F}=73.1 \%\right)$ was observed. No matter which carbohydrate source used, silage made from shrimp waste remained stable for 120 days and may be used in diets to Nile tilapia.
\end{abstract}

Keywords: biological silage, shrimp waste, Xiphopenaeus kroyeri, Oreochromis niloticus, digestibility

Recebido em 30 de setembro de 2005

Aceito em 19 de abril de 2007

*Autor para correspondência (corresponding author)

E-mail: emviegas@usp.br 


\section{INTRODUÇÃO}

Os resíduos de camarão provenientes da indústria processadora sofrem rápida decomposição e, por isso, devem ser prontamente utilizados. Tradicionalmente, sua utilização restringia-se à produção de farinha de camarão, mas recentemente novas alternativas de aproveitamento têm sido avaliadas, como a silagem de camarão (Fagbenro, 1996; Fagbenro e Bello-Ollusorj, 1997; Plascencia-Jatomea et al., 2002).

O princípio da preservação dos resíduos do processamento de pescado, mediante a elaboração de silagem, deve-se principalmente à redução do $\mathrm{pH}$ e à hidrólise protéica da massa residual, por dois métodos principais: 1) adição de ácidos orgânicos ou inorgânicos, ou 2) processo biológico de fermentação por bactérias láticas, o qual gera ácido lático aumentando conseqüentemente a acidez do meio. A fermentação tem sido aplicada à fabricação de silagem de peixes há muitos anos e representa uma tecnologia simples, de baixo custo e muito interessante para ser aplicada em países em desenvolvimento (Fagbenro, 1996).

Para resíduos de crustáceos, o processo fermentativo da silagem vem sendo utilizado com vários propósitos como: obtenção de glucosaminas (Ferrer et al., 1996); alimento para ruminantes (Evers e Carrol, 1998); substituto da farinha de peixe em dietas para tilápia-do-nilo (Plascencia-Jatomea et al., 2002); método de recuperação da quitina presente na carapaça desses crustáceos (Cira et al., 2002); e substrato para Verticillium lecanii na produção de $\beta-\mathrm{N}$ acetilhexosaminidase (Matsumoto et al., 2004).

Cabeças de camarão de água doce (Macrobrachium vollenhovenii) submetidas à fermentação com melaço de cana-de-açúcar ou amido de mandioca, como fonte de carboidrato, e com Lactobacillus plantarum a $30^{\circ} \mathrm{C}$, produziram silagens com $\mathrm{pH}$ próximo à neutralidade $(6,7)$ no início da estocagem, diminuindo para valores ao redor de 4,6 após 7 dias e para 4,0 ao $30^{\circ}$ dia de estocagem (Fagbenro, 1996).

Evers e Carrol (1996) utilizaram resíduos de camarão com diferentes quantidades de sal $(\mathrm{NaCl})$ e fontes de carboidratos na elaboração de silagens para alimentação de bovinos. Os autores observaram que a baixa quantidade de carboidrato pode limitar o crescimento das bactérias produtoras de ácido lático, pois os valores de $\mathrm{pH}$ sempre estiveram maiores que 4,5, tornando a dieta imprópria para alimentação de bovinos, devido à provável presença de bactérias patogênicas.

Plascencia-Jatomea et al. (2002) utilizaram hidrolisado protéico de silagem de cabeças de camarão (Penaeus spp.) na alimentação de tilápias-do-nilo e verificaram que a substituição da farinha de peixe com 10 e $15 \%$ de hidrolisado mostrou melhor resultado que a dieta-controle contendo a farinha de peixe como fonte protéica.

Os objetivos deste trabalho foram avaliar três resíduos/subprodutos agroindustriais (camarão, melaço de cana-de-açúcar e farinha láctea) na elaboração de silagens biológicas e determinar o coeficiente de digestibilidade aparente da proteína para a tilápia-do-nilo.

\section{MATERIAL E MÉTODOS}

Os resíduos do processamento do camarão sete barbas foram adquiridos no Entreposto de Pescado em Santos, SP, e transportados em caixas isotérmicas para o laboratório de aqüicultura da Faculdade de Zootecnia e Engenharia de Alimentos da Universidade de São Paulo, Pirassununga, SP. Para a produção das silagens, os resíduos foram moídos em moedores de carne ${ }^{1}$ e acondicionados em baldes com tampa e capacidade para 20 litros. Dois tipos de silagens fermentadas foram elaborados alterando-se a fonte de carboidratos: melaço de cana-de-açúcar (SM) e resíduos da produção de farinha láctea (varredura) da indústria Nestlé (SF), com três repetições.

Para a elaboração da SM foram adicionados à biomassa de resíduos de camarão, $15 \%(\mathrm{p} / \mathrm{p})$ de melaço de cana-de-açúcar, $10 \%(\mathrm{p} / \mathrm{p})$ de iogurte sem sabor com a data de validade vencida (sem valor comercial), $0,25 \%(\mathrm{p} / \mathrm{p})$ de ácido sórbico e $1 \%$ de ácido fórmico $(\mathrm{v} / \mathrm{p})$ ao oitavo dia. A SF foi elaborada com a adição de $15 \%(\mathrm{p} / \mathrm{p})$ de varredura de farinha láctea, $10 \%(\mathrm{p} / \mathrm{p})$ do mesmo iogurte utilizado na SM, $0,25 \%(\mathrm{p} / \mathrm{p})$ de ácido sórbico e $1 \%$ de ácido fórmico (v/p) ao oitavo dia (Fig. 1).

${ }^{1}$ D1 1411, Brasiaço - Petrópolis, RJ. 
Produção, caracterização e avaliação biológica...

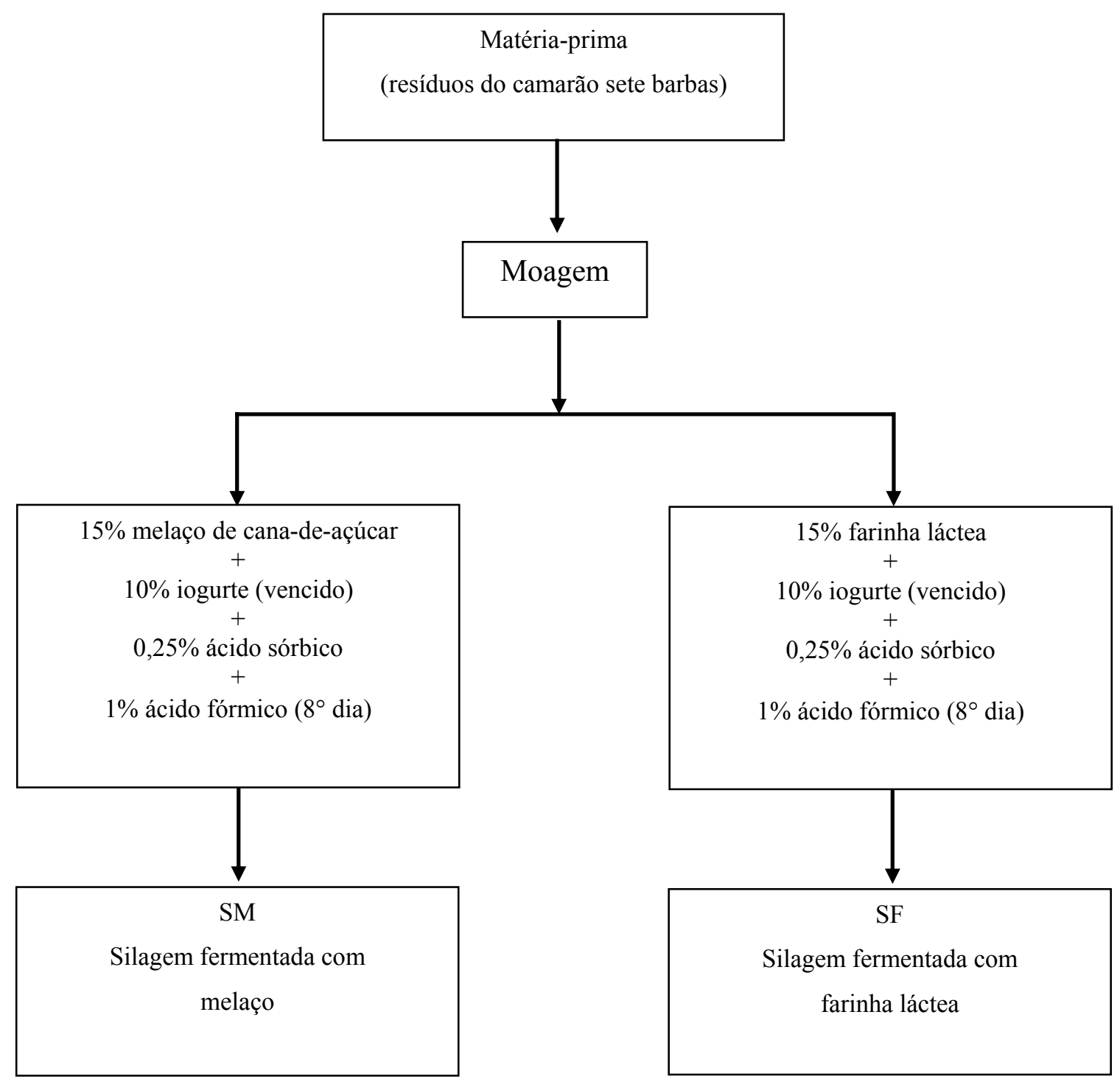

Figura 1. Fluxograma de elaboração das silagens fermentadas de resíduos de camarão.

$\mathrm{O} \mathrm{pH}$ das silagens foi determinado diariamente com pHgâmetro digital ${ }^{2}$, até o oitavo dia de estocagem e ao $10^{\circ}, 20^{\circ}, 30^{\circ}, 60^{\circ}, 90^{\circ}$ e $120^{\circ}$ dias. A determinação da produção de ácido lático foi feita diariamente até o sétimo dia e ao $14^{\circ}$, $30^{\circ}, 60^{\circ}, 90^{\circ}$ e $120^{\circ}$ dias, de acordo com o método colorimétrico proposto por Silva (1981).

As análises para determinar a composição centesimal da matéria-prima (resíduos de camarão) e das amostras de silagens foram

${ }^{2}$ DM-2, Digimed - São Paulo, SP realizadas segundo AOAC (Official..., 1990) no $1^{\circ}, 7^{\circ}, 30^{\circ}, 60^{\circ}, 90^{\circ}$ e $120^{\circ}$ dias após a elaboração das silagens. A matéria seca foi obtida por secagem das amostras em estufa a $105^{\circ} \mathrm{C}$ por 16 horas. O conteúdo de proteína bruta foi determinado pelo método de semimicroKjeldahl, corrigindo-se o teor de nitrogênio total mediante multiplicação pelo fator 6,25 . O conteúdo de lipídeos foi determinado por extração com éter de petróleo por seis horas (Soxhlet), e o conteúdo de cinzas foi obtido pela queima da amostra em mufla a $500^{\circ} \mathrm{C}$ por quatro horas. 
Após 30 dias de armazenamento das silagens à temperatura ambiente $\left(28^{\circ} \mathrm{C}\right)$, procedeu-se ao ensaio de digestibilidade in vivo para a tilápiado-nilo. Foram elaboradas duas dietas-teste com $26 \%$ de proteína bruta e $4200 \mathrm{Kcal}$ de energia bruta: dieta elaborada com SM (DSM) e dieta elaborada com SF (DSF) contendo 69,9\% de dieta referência (Tab. 1), 0,1\% de óxido de cromo, que foi utilizado como marcador inerte, e $30 \%$ de matéria seca das silagens preparadas. As dietas-teste foram peletizadas em moedores de carne $^{3}$, resultando em peletes com aproximadamente $15 \mathrm{~mm}$ de comprimento e $5 \mathrm{~mm}$ de diâmetro.

Tabela 1. Dietas teste utilizadas no ensaio de digestibilidade in vivo para tilápia-do-nilo

\begin{tabular}{lcc}
$\begin{array}{l}\text { Dietas } \\
\text { teste }\end{array}$ & $\begin{array}{c}\text { Dieta referência } \\
(\mathrm{g})^{\mathrm{a}} \\
(\text { peso seco) }\end{array}$ & $\begin{array}{c}\text { Ingrediente Teste } \\
(\mathrm{g}) \\
\text { (peso úmido) }\end{array}$ \\
\hline $\mathrm{DSM}$ & 700,00 & 1498,50 \\
$\mathrm{DSF}$ & 700,00 & 1409,80 \\
\hline
\end{tabular}

a: $16 \%$ milho, $26 \%$ farelo de trigo, $14 \%$ farelo de arroz, $30 \%$ farelo de soja, $1 \%$ óleo de soja, $12 \%$ farinha de peixe, $0,9 \%$ suplemento mineral vitamínico e $0,1 \%$ óxido de cromo.

$\mathrm{DSM}=$ dieta elaborada com silagem de melaço de cana-de-açúcar; DSF= dieta elaborada com silagem de farinha láctea.

No experimento de digestibilidade foram utilizados 150 juvenis de tilápia-do-nilo (peso médio 150 gramas) mantidos em seis aquários de alimentação com capacidade de 200 litros, com aeração e abastecimento constante, na densidade de 25 peixes/aquário.

Os peixes foram submetidos às dietas experimentais por um período de cinco dias antes de se iniciar a coleta das fezes. A alimentação com as dietas-teste e dieta referência foi feita $a d$ libitum, duas vezes ao dia $(8 \mathrm{~h} 30 \mathrm{~min}-9 \mathrm{~h}$ e 16h30min-17h) e a coleta das fezes foi realizada por decantação, em três aquários de coleta com capacidade de 2201.

A determinação do teor de óxido de cromo nas fezes e nas dietas foi realizada pelo método de digestão ácida segundo Furukawa e Tsukahara (1996). Os coeficientes de digestibilidade aparente da fração protéica das dietas foram estimados segundo a equação descrita por Nose (1960). A digestibilidade aparente da proteína (PD) foi calculada de acordo com a fórmula proposta por Cho e Slinger (1979).

Utilizou-se delineamento inteiramente ao acaso, com dois tratamentos e três repetições. Os resultados obtidos para composição centesimal, nitrogênio não protéico (NNP), coeficientes de digestibilidade aparente da proteína bruta $\left(\mathrm{CDA}_{\mathrm{PB}}\right)$ e proteína digestível (PD) foram submetidos à análise de variância e para comparação das médias utilizou-se o teste Tukey $(\mathrm{P}<0,05)$.

\section{RESULTADOS E DISCUSSÃO}

Os valores de $\mathrm{pH}$ das silagens, inicialmente elevados $(\mathrm{SM}=6,98$ e $\mathrm{SF}=7,24)$, diminuíram até o sexto dia após a elaboração (Tab. 2), devido à produção de ácido lático proveniente da fermentação dos carboidratos pelas bactérias presentes no iogurte. No sétimo dia de estocagem, os valores de $\mathrm{pH}$ aumentaram, $\mathrm{SM}=$ 5,69 e $\mathrm{SF}=5,54$, provavelmente ocasionados pela queda de produção de ácido lático (Fig. 2). Valores de $\mathrm{pH}$ acima de 5,0 possibilitam o crescimento de microrganismos patógenos $\mathrm{e}$ deteriorantes, tornando a silagem imprópria para o uso (Vidotti et al., 2002). Dessa forma, adicionou-se $1 \%(\mathrm{v} / \mathrm{p})$ de ácido fórmico no oitavo dia, o que causou a redução e a estabilidade do $\mathrm{pH}$ das silagens até o $120^{\circ}$ dia de armazenamento. Fagbenro (1996), ao trabalhar com silagem de resíduos de camarão (Macrobrachium vollenhovenii), observou instabilidade do $\mathrm{pH}$, com uma significativa elevação dos valores, de 4,1 a 5,0, após 180 dias de estocagem, atribuindo esse fato aos efeitos tamponantes dos aminoácidos e de outros sais presentes na silagem, ou ainda à parcial neutralização do ácido lático pelo cálcio da quitina presente na carapaça desses crustáceos.

Os resíduos de camarão apresentaram $18,97 \mathrm{~g} .100 \mathrm{~g}^{-1}$ de matéria seca, $31,68 \mathrm{~g} \cdot 100 \mathrm{~g}^{-1} \mathrm{de}$ proteína bruta, $1,69 \mathrm{~g} .100 \mathrm{~g}^{-1}$ de extrato etéreo e $48,13 \mathrm{~g} .100 \mathrm{~g}^{-1}$ de cinzas. A análise do NNP indicou valores de $214,20 \mathrm{mg} \quad \mathrm{N} .100 \mathrm{~g}^{-1}$ no resíduo. 
Tabela 2. Valores médios de $\mathrm{pH}$ das silagens fermentadas, no dia da elaboração e durante a estocagem até 120 dias

\begin{tabular}{ccc}
\hline Período (dias) & SM & SF \\
\hline 1 & 6,98 & 7,24 \\
2 & 6,61 & 6,63 \\
3 & 6,45 & 6,22 \\
4 & 5,96 & 5,70 \\
5 & 5,70 & 5,50 \\
6 & 5,60 & 5,40 \\
7 & 5,69 & 5,54 \\
8 & $4,84^{\mathrm{a}}$ & $4,42^{\mathrm{a}}$ \\
10 & 4,66 & 4,59 \\
20 & 4,69 & 4,60 \\
30 & 4,66 & 4,61 \\
60 & 4,66 & 4,66 \\
90 & 4,59 & 4,56 \\
120 & 4,55 & 4,52 \\
\hline
\end{tabular}

a: adição de $1 \%$ de ácido fórmico; SM: silagem fermentada de resíduos de camarão com melaço de cana-de-açúcar; SF: silagem fermentada de resíduos de camarão com farinha láctea.
Logo após a elaboração, as silagens apresentaram composição centesimal semelhante à do resíduo de camarão. Houve efeito significativo $(\mathrm{P}<0,05)$ do tempo de estocagem da $\mathrm{SM}$ e SF sobre os teores de matéria seca (MS), PB, matéria mineral (MM) e NNP (Tab. 3 e 4). A variação nos valores de MS durante a estocagem pode estar relacionada ao fato de o processo de ensilagem ter transformado a biomassa semisólida em líquida (Shirai et al., 2001), evidenciando maior quantidade de MS no dia de elaboração em relação aos demais dias de estocagem.

Os resíduos de camarão apresentaram elevados teores de cinzas $(48 \%)$, que diminuíram com o processo de fermentação (Tab. 3 e 4) e se estabilizaram a partir do sétimo dia para as duas silagens. A diminuição de cinzas também foi observada por Meyers e Benjamin (1987) em silagens ácidas, e por Fox et al. (1994) e Fagbenro (1996), em silagens fermentadas de cabeças de camarão.

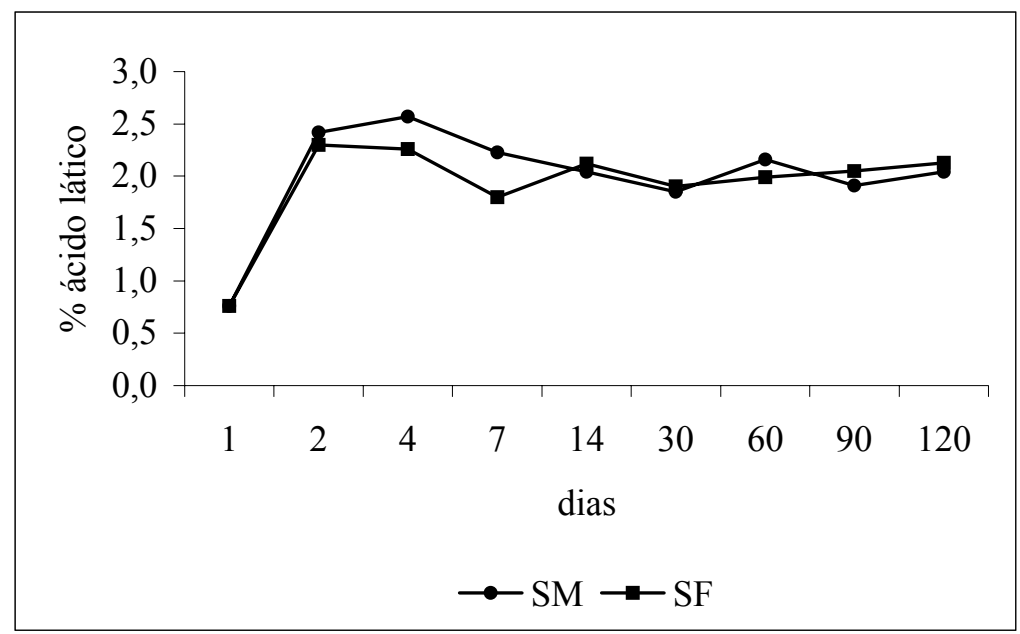

Figura 2. Produção de ácido lático das silagens fermentadas com resíduos de camarão e melaço de canade-açúcar (SM) ou varredura de farinha láctea (SF) durante a estocagem.

O aumento dos teores de NNP foi pronunciado nos sete primeiros dias de fermentação, praticamente duplicando os valores iniciais presentes na matéria-prima e nas silagens no dia de elaboração. Durante o armazenamento, o aumento de NNP na SM foi linear até alcançar o máximo, aos 120 dias $\left(548,80 \mathrm{mg} \mathrm{N} .100 \mathrm{~g}^{-1}\right)$. Na
SF, o aumento foi linear até 60 dias de estocagem, houve queda aos 90 dias e novo aumento aos 120 dias. Nas duas silagens, o valor máximo de NNP atingido aos 120 dias coincide com os menores teores de $\mathrm{PB} \quad(\mathrm{SM}=$ $22,41 \mathrm{~g} .100 \mathrm{~g}^{-1}$ e $\mathrm{SF}=24,62 \mathrm{~g} .100 \mathrm{~g}^{-1}$ ). 


\section{Gonçalves e Viegas}

Tabela 3. Valores médios da composição centesimal e teores de nitrogênio não protéico das silagens fermentadas com resíduos de camarão e melaço de cana-de-açúcar (SM) no primeiro dia de elaboração e durante a estocagem

\begin{tabular}{|c|c|c|c|c|c|}
\hline & \multicolumn{4}{|c|}{ Nutriente $\left(\mathrm{g} .100 \mathrm{~g}^{-1}\right)$} & \multirow{2}{*}{$\begin{array}{c}\text { NNP } \\
\left(\mathrm{mg} \mathrm{N}^{2} 100 \mathrm{~g}^{-1}\right)\end{array}$} \\
\hline & MS & PB & $\mathrm{EE}$ & MM & \\
\hline Valor de F & $10,16^{*}$ & $9,73 *$ & $2,01 \mathrm{~ns}$ & $9,72 *$ & $295,72 *$ \\
\hline $\mathrm{CV}(\%)$ & 3,32 & 3,07 & 10,79 & 2,67 & 2,83 \\
\hline \multicolumn{6}{|c|}{ Tempo (dias) } \\
\hline 1 & $23,52 \mathrm{a}$ & $20,97 b$ & $2,99 a$ & $30,81 b$ & $215,60 d$ \\
\hline 7 & $20,31 b$ & $23,37 \mathrm{a}$ & $2,52 \mathrm{a}$ & $35,00 \mathrm{a}$ & $385,00 \mathrm{c}$ \\
\hline 30 & $20,02 b$ & $23,87 \mathrm{a}$ & $2,69 a$ & $34,97 \mathrm{a}$ & $473,20 b$ \\
\hline 60 & $21,14 b$ & $24,20 \mathrm{a}$ & $2,49 a$ & $34,07 \mathrm{a}$ & $486,40 \mathrm{~b}$ \\
\hline 90 & $20,34 b$ & $24,25 \mathrm{a}$ & $3,09 a$ & $34,87 \mathrm{a}$ & $530,60 \mathrm{a}$ \\
\hline 120 & $20,77 b$ & $22,41 \mathrm{ab}$ & $2,79 a$ & $34,71 \mathrm{a}$ & $548,80 \mathrm{a}$ \\
\hline
\end{tabular}

* Significativo a $\mathrm{P}<0,05$; ns: não significativo

MS: matéria seca; PB: proteína bruta; EE: extrato etéreo; MM: matéria mineral; NNP: nitrogênio não protéico. Médias nas colunas seguidas de letras distintas diferem entre si pelo teste Tukey $(\mathrm{P}<0,05)$

Tabela 4. Valores médios da composição centesimal e teores de nitrogênio não protéico das silagens fermentadas com resíduos de camarão e varredura de farinha láctea (SF) no primeiro dia de elaboração e durante a estocagem

\begin{tabular}{|c|c|c|c|c|c|}
\hline & \multicolumn{4}{|c|}{ Nutriente (g.100g $\left.\mathrm{g}^{-1}\right)$} & \multirow{2}{*}{$\begin{array}{c}\text { NNP } \\
\left(\mathrm{mg} \mathrm{N} .100 \mathrm{~g}^{-1}\right)\end{array}$} \\
\hline & MS & PB & $\mathrm{EE}$ & MM & \\
\hline Valor de F & $51,53 *$ & $38,04 *$ & $3,85 \mathrm{~ns}$ & $20,01 *$ & $42,75^{*}$ \\
\hline CV $(\%)$ & 2,71 & 2,65 & 9,10 & 4,74 & 8,15 \\
\hline \multicolumn{6}{|c|}{ Tempo (dias) } \\
\hline 1 & $27,41 \mathrm{a}$ & $20,04 \mathrm{c}$ & $2,75 a$ & $22,62 b$ & $214,20 d$ \\
\hline 7 & $22,02 b$ & $23,37 b$ & $2,96 \mathrm{a}$ & $29,94 a$ & $404,67 \mathrm{c}$ \\
\hline 30 & $21,11 b$ & $25,57 \mathrm{a}$ & $2,66 \mathrm{a}$ & $30,92 \mathrm{a}$ & $498,27 \mathrm{bc}$ \\
\hline 60 & $22,54 b$ & $25,55 \mathrm{a}$ & $2,69 \mathrm{a}$ & $32,91 \mathrm{a}$ & $544,60 \mathrm{ab}$ \\
\hline 90 & $21,49 \mathrm{~b}$ & $26,25 \mathrm{a}$ & $3,32 \mathrm{a}$ & $31,26 \mathrm{a}$ & $501,20 b c$ \\
\hline 120 & $21,77 \mathrm{~b}$ & $24,62 \mathrm{ab}$ & $3,31 \mathrm{a}$ & $31,13 \mathrm{a}$ & $630,00 \mathrm{a}$ \\
\hline
\end{tabular}

* Significativo a $\mathrm{P}<0,05$; ns: não significativo

MS: matéria seca; PB: proteína bruta; EE: extrato etéreo; MM: matéria mineral; NNP: nitrogênio não protéico.

Médias nas colunas seguidas de letras distintas diferem entre si pelo teste Tukey $(\mathrm{P}<0,05)$

As variações nos valores de NNP durante a estocagem podem ser atribuídas ao aumento da hidrólise das proteínas por enzimas bacterianas (Jose-Joseph et al., 1998), ou mesmo por enzimas endógenas musculares dos resíduos de camarão.

Os valores de composição centesimal, $\mathrm{CDA}_{\mathrm{PB}} \mathrm{e}$ $\mathrm{PD}$ foram analisados com 30 dias de estocagem. Houve efeito significativo $(\mathrm{P}<0,05)$ sobre os teores de MS e MM (Tab. 5). Isso pode ser atribuído aos ingredientes adicionados às silagens como fonte de carboidratos, pois o melaço de cana-de-açúcar apresentou maior teor de umidade que a varredura da farinha láctea.

Os $\mathrm{CDA}_{\mathrm{PB}}$ foram altos mas não houve diferença significativa $(\mathrm{P}>0,05)$ entre os tipos de silagens.
Vidotti et al. (2002) utilizaram dietas com silagens fermentadas ou ácidas elaboradas com descarte de peixes de água doce e salgada e não observaram diferenças significativas entre os tratamentos $(\mathrm{P}>0,05)$ quanto ao $\mathrm{CDA}_{\mathrm{PB}}$ para Piaractus mesopotamicus. Fagbenro (1996) observou valores de 81,4 a $90,8 \%$ de $\mathrm{CDA}_{\mathrm{PB}}$ em dietas com silagens fermentadas de cabeça de camarão oferecidas para Clarias gariepinus. Boscolo et al. (2004) obtiveram 88,8\% de $\mathrm{CDA}_{\mathrm{PB}}$ da farinha de camarão (Macrobrachium amazonicum) para a tilápia-do-nilo. Essas diferenças de $\mathrm{CDA}_{\mathrm{PB}}$ podem estar relacionadas às espécies de camarão utilizadas na elaboração das silagens, bem como ao tamanho ou à espécie de peixe utilizada no experimento de digestibilidade. 
Tabela 5. Valores médios da composição centesimal das silagens fermentadas e seus coeficientes de digestibilidade aparente da proteína ( $\mathrm{CDA}_{\mathrm{PB}}$ ) e proteína digestível (PD) para juvenis de tilápia-do-nilo

\begin{tabular}{|c|c|c|c|c|c|c|}
\hline & \multicolumn{4}{|c|}{ Nutriente $\left(\right.$ g. $\left.100 \mathrm{~g}^{-1}\right)$} & \multirow{2}{*}{$\begin{array}{c}\mathrm{CDA}_{\mathrm{PB}} \\
(\%) \\
\end{array}$} & \multirow{2}{*}{$\begin{array}{l}\text { PD } \\
(\%)\end{array}$} \\
\hline & MS & PB & $\mathrm{EE}$ & $\mathrm{MM}$ & & \\
\hline $\begin{array}{l}\text { Valor de F } \\
\text { CV (\%) }\end{array}$ & $\begin{array}{c}13,56^{*} \\
2,02\end{array}$ & $\begin{array}{c}5,27 \mathrm{~ns} \\
3,67\end{array}$ & $\begin{array}{c}0,03 \mathrm{~ns} \\
8,47\end{array}$ & $\begin{array}{c}76,29^{*} \\
1,73\end{array}$ & $\begin{array}{c}1,48 \mathrm{~ns} \\
6,82\end{array}$ & $\begin{array}{c}0,06 \mathrm{~ns} \\
3,50\end{array}$ \\
\hline Silagens & & & & & & \\
\hline SM & $20,02 b$ & $23,87 \mathrm{a}$ & $2,69 a$ & $34,97 \mathrm{a}$ & $78,25 a$ & $18,57 \mathrm{a}$ \\
\hline SF & $21,28 \mathrm{a}$ & $25,57 \mathrm{a}$ & $2,66 \mathrm{a}$ & $30,92 b$ & $73,12 \mathrm{a}$ & $18,71 \mathrm{a}$ \\
\hline
\end{tabular}

* Significativo a $\mathrm{P}<0,05$; ns: não significativo

MS: matéria seca; PB: proteína bruta; EE: extrato etéreo; MM: matéria mineral; SM: silagem fermentada de resíduos de camarão com melaço de cana-de-açúcar (após 30 dias de estocagem); SF: silagem fermentada de resíduos de camarão com farinha láctea (após 30 dias de estocagem)

Médias nas colunas seguidas de letras distintas diferem entre si pelo teste $\mathrm{F}(\mathrm{P}<0,05)$

Os valores de digestibilidade são importantes parâmetros para determinar a utilização de ingredientes na alimentação animal. Dessa forma, os valores de $\mathrm{CDA}_{\mathrm{PB}}$ apresentados sugerem que as silagens de resíduos de camarão podem ser uma alternativa para alimentação de peixes e destino de resíduos do processamento, garantindo assim, a sustentabilidade da aqüicultura.

\section{CONCLUSÃO}

Conclui-se que, independente da fonte de carboidrato, as silagens de resíduos de camarãosete-barbas elaboradas neste trabalho mantiveram-se praticamente estáveis durante 120 dias, e com 30 dias de estocagem apresentaram altos valores de coeficientes de digestibilidade aparente de proteína bruta para juvenis de tilápiado-nilo.

\section{AGRADECIMENTOS}

Os autores agradecem à FAPESP (Fundação de Amparo à Pesquisa do Estado de São Paulo) pela bolsa de estudos concedida à primeira autora e à Faculdade de Zootecnia e Engenharia de Alimentos da Universidade de São Paulo.

\section{REFERÊNCIAS BIBLIOGRÁFICAS}

BOSCOLO, W.R.; HAYASHI, C.; MEURER, F. Digestibilidade aparente da energia e proteína das farinhas de resíduo da filetagem da tilápiado-nilo (Oreochromis niloticus) e da corvina (Plagioscion squamosissimus) e farinha integral do camarão canela (Macrobrachium amazonicum) para a tilápia-do-nilo. Rev. Bras. Zootec., v.33, p.8-13, 2004.

CHO, C.Y.; SLINGER, S.I. Apparent digestibility measurement infeedstuff for rainbow trout. In: WORLD SYMPOSIUM ON FINFISH NUTRITION AND FISHFEED TECHNOLOGY, 1978, Hamburgo. Proceedings... Hamburgo, 1979. p.239-247.

CIRA, L.A.; HUERTA, S.; HALL, G.M. et al. Pilot scale lactic acid fermentation of shrimp waste for chitin recovery. Proc. Biochem., v.37, p.1359-1366, 2002.

EVERS, D.J.; CAROLL, D.J. Ensiling saltpreserved shrimp waste with grass straw and molasses. Anim. Feed Sci. Technol., v.71, p.241249, 1998.

EVERS, D.J.; CARROL, D.J. Preservation of crab or shrimp waste as silage for cattle. Anim. Feed Sci. Technol., v.59, p.233-244, 1996.

FAGBENRO, O.A. Preparation, properties and preservation of lactic acid fermented shrimp heads. Food Res. Int., v.29, p.595-599, 1996.

FAGBENRO, O.A.; BELLO-OLUSOJI, O.A. Preparation, nutrient composition and digestibility of fermented shrimp head silage. Food Chem., v.60, p.489-493, 1997.

FERRER, J.; PAEZ, G.; MARMOL, Z. et al. Acid hydrolysis of shrimp-shell wastes and the production of single cell protein from the hydrolysate. Biores. Technol., v.57, p.55-60, 1996.

FOX, C.J.; BLOW, P.; BROWN, J.H. et al. The effect of various processing methods on the physical and biochemical properties of shrimp 
head meals and their utilization by juvenile Penaeus monodon Fab. Aquaculture, v.122, p.209-226, 1994.

FURUKAWA A.; TSUKAHARA, H. On the acid digestion method for the determination of chromic oxyde as an index substance in the study of digestibility of fish feed. Bull. Jpn. Soc. Fish., v.32, p.502-506, 1966.

JOSE-JOSEPH, P.A.; PERIGREEN, C.; GOPALAKRISHNA IYER, T.S. Storage characteristics of cultured Penaeus indicus in ice and at ambient temperature. Fish. Technol., v.35, p.84-89, 1998.

MATSUMOTO, Y.; SAUCEDO-CASTAÑEDA, G.; REVAH, S. et al. Production of $\beta-\mathrm{N}-$ acetilhexosaminidase of Verticillium lecanii by solid state and submerged fermentations utilizing shrimp waste silage as substrate and inducer. Proc. Biochem., v.39, p.665-671, 2004.

MEYERS, S.P.; BENJAMIN, G. Feeding values of crustacean waste can be improved through proper ensilage treatment. Feedstuffs, v.59, p.1213, 1987.

NOSE, T. On the digestion of food protein by gold-fish (Carassius auratus L.) and rainbow trout (Salmo irideus G.). Bull. Freshw. Fish. Res. Lab., v.10, p.11-22. 1960.

OFFICIAL methods of analysis. 14.ed. Washington, DC: AOAC, 1990. 1141p.

PLASCENCIA-JATOMEA, M.; OLVERANOVOA, M.A.; ARREDONDO-FIGUEROA, J.L. et al. Feasibility of fishmeal replacement by shrimp head silage protein hydrolysate in Nile Tilapia (Oreochromis niloticus L.) diets. J. Sci. Food Agric., v.82, p.753-759, 2002.

SHIRAI, K.; GUERRERO, J.; HUERTA, S. et al. Effect of initial glucose concentration and inoculation level of lactic acid bacteria in shrimp waste ensilation. Enzyme Microb. Technol., v.38, p.446-452, 2001.

SILVA, D. J. Análise de alimentos: métodos químicos e biológicos. Viçosa: Imprensa Universitária UFV, 1981. 165p.

VIDOTTI, R. M.; CARNEIRO, D. J.; MACEDO-VIEGAS, E. M. Acid and fermented silage characterization and determination of apparent digestibility coefficient of crude protein for pacu Piaracutus mesopotamicus. J. World Aquac. Soc., v.33, p.57-62, 2002. 